\title{
Inheritance of DNA Methylation in Coprinus cinereus
}

\author{
MIRIAM E. ZOLAN ${ }^{*}$ AND PATRICIA J. PUKKILA \\ Department of Biology and Curriculum in Genetics, University of North Carolina, Chapel Hill, North Carolina 27514
}

Received 29 July 1985/Accepted 9 October 1985

\begin{abstract}
We examined the inheritance of 5-methylcytosine residues at a centromere-linked locus in the basidiomycete Coprinus cinereus. Although methylated and unmethylated tracts were inherited both mitotically and meiotically the lengths of these tracts were variable. This variation was not confined to any one phase of the life cycle of the organism, and it usually involved the simultaneous de novo methylation of at least four $\mathrm{HpaII-MspI}$ sites. We also found that the higher levels of methylation at this locus were transmitted through meiosis, regardless of the level of methylation of the homologous chromosome.
\end{abstract}

Postreplicative methylation of DNA cytosine residues is a common feature of procaryotic and eucaryotic DNAs. In eucaryotes, cytosine methylation is believed to be a controlling mechanism in gene expression (for examples, see references 5 and 14) and development $(7,8)$. Since most methylation in animals and fungi is at the nucleotide doublet $\mathrm{CpG}(2$, 17), the isoschizomer pair of restriction endonucleases, $H p a I I$ and $M s p I$, has provided a powerful tool for the study of the methylation patterns of specific DNA sequences (3, 18). These two enzymes recognize the same sequence $\left(5^{\prime}\right.$ CCGG-3'), but HpaII is sensitive to $\mathrm{CpG}$ methylation, while $M s p I$ is sensitive to $\mathrm{CpC}$ methylation (9).

Coprinus cinereus is a particularly useful organism for the study of eucaryotic DNA methylation. This basidiomycete has a small nuclear genome size of 38,000 kilobase pairs $(\mathrm{kb})$ (6), which facilitates molecular analyses. In addition, genetic studies and experimental manipulation of all phases of its life cycle are straightforward and simple. We have shown previously that the nuclear genome of this fungus is extensively methylated at the nucleotide doublet CpG (M. E. Zolan and P. J. Pukkila, in Molecular Genetics of Filamentous Fungi, in press). In that study, we also examined the inheritance of DNA methylation at a centromere-linked locus, termed 16-1, which is methylated in one geographical isolate (Okayama-7) but not in others. Tetrad analysis of progeny from a cross between Okayama-7 and PJP52 (which is unmethylated at 16-1) revealed that methylated tracts are inherited $2: 2$ during meiosis. That is, progeny that received the chromosome containing locus 16-1 from Okayama-7 were always methylated at that locus, and progeny that inherited locus 16-1 from PJP52 were not methylated at that locus. However, we observed altered lengths of methylated tracts among the methylated progeny. In this study, we asked whether these alterations are a direct consequence of the meiotic process, and we also asked whether the altered tracts resulting from de novo methylation are transmitted as simple Mendelian alleles.

\section{MATERIALS AND METHODS}

C. cinereus strains and growth. The two parents, Okayama-7 and PJP52, of MZ1, the first cross in this study, were described previously (4). The remainder of the strains used were progeny of MZ1 and are described in Table 1. Growth of the cultures for DNA extraction was as in the

\footnotetext{
* Corresponding author.

† Present address: Department of Natural Sciences, University of Michigan-Dearborn, Dearborn, MI 48128.
}

alternate method described by Cassidy et al. (4). To isolate oidia, $5 \mathrm{ml}$ of sterile $\mathrm{H}_{2} \mathrm{O}$ was poured onto the surface of a confluent plate of a monokaryotic culture. The surface was scraped with a sterile glass rod or spatula, and the liquid was collected and filtered through sterile glass wool. Veil cells were scraped off pachytene-stage fruiting bodies and homogenized for $60 \mathrm{~s}$ in $15 \mathrm{ml}$ of sterile $\mathrm{H}_{2} \mathrm{O}$ at high speed in a Waring blender. Random basidiospores were isolated as described by Anderson (1). In all cases, germinated spores or veil cells were isolated when only a few hyphae were present to ensure the isolation of colonies deriving from single spores or veil cell nuclei. $C$. cinereus is a particularly useful organism for this type of study, because all of the spores are large, settle quickly out of solution, and are never airborne, which greatly minimizes the possibility of cross-contamination of cultures. Tetrads of MZ1 were isolated by the method of Moore (12) except that a micromanipulator was not used. For cross MZ4, a micromanipulator was used to remove individual tetrads from dried gill segments.

DNA extraction. DNA extraction from small amounts of tissue of the tetrads of MZ1 was as described previously (4). DNA extraction from the remainder of the strains in the study was by our modification of the procedures of Murray and Thompson (13) and Saghai-Maroof et al. (15). Tissue was quick frozen in liquid nitrogen and lyophilized either in a Savant Speed-Vac or in a VirTis lyophilizer for several hours or overnight. The dried tissue was then stored at room temperature in sealed bags with desiccant until use. Tissue was powdered in a mortar and pestle at room temperature. About $40 \mathrm{mg}$ of this powder was then transferred to a microcentrifuge tube, and 500 to $600 \mu$ l of extraction buffer (1\% hexadecyltrimethylammonium bromide [Sigma H-5887], $0.7 \mathrm{M} \mathrm{NaCl}, 50 \mathrm{mM}$ Tris hydrochloride [pH 8.0], $10 \mathrm{mM}$ EDTA, 1\% 2-mercaptoethanol) (13) were added. The powder was mixed with the buffer by using a P1000 Gilson Pipetman, vortexed briefly, and incubated at $60^{\circ} \mathrm{C}$ for 30 min. An equal volume of SEVAG (chloroform-isoamyl alcohol, 24:1 [ $[\mathrm{vol} / \mathrm{vol}])$ was added, and the samples were vortexed for a few seconds and spun in a microcentrifuge (Fisher Scientific Co.) for $5 \mathrm{~min}$. Three phases resulted from this centrifugation: a clear amber aqueous phase; a thick, solid interphase containing cellular debris; and the SEVAG phase. The aqueous phase was transferred to a fresh tube, and an equal volume of isopropanol was added. The samples were mixed by inversion, and the nucleic acid pellet precipitated immediately. The samples were spun for $30 \mathrm{~s}$ in a microcentrifuge, the supernatant was poured off, and the samples were inverted on paper towels for a few seconds to 
TABLE 1. Description of crosses

\begin{tabular}{|c|c|}
\hline Cross & Strains" \\
\hline $\begin{array}{l}\text { MZ1. } \\
M Z 2 \\
M Z 3 \\
M Z 4\end{array}$ & $\begin{array}{l}\text { Okayama-7 (2.5) } \times \text { PJP } 52(1.5) \\
\text { MZ1-23B }^{b}(2.5) \times \mathrm{MZ1}-15 \mathrm{C}(5.2) \\
\mathrm{MZ2}-21(5.2) \times \mathrm{MZ2-22}(5.2) \\
\mathrm{MZ2-28}(5.2) \times \text { Okayama-7 (2.5) }\end{array}$ \\
\hline
\end{tabular}

"Numbers in parentheses are the sizes, in kilobase pairs. of the major Hpall fragments of locus 16-1.

${ }^{h}$ Isolate numbers followed by a letter A. B. C. or D indicate that the isolate was from a tetrad. Isolate numbers not followed by a letter indicate random isolates. All strains are basidiospore isolates.

drain. Occasionally, pellets contained significant amounts of an oily substance. This could be removed with a P200 Gilson Pipetman. The samples were suspended in $300 \mu$ l of TE (10 $\mathrm{mM}$ Tris hydrochloride [pH 8.0], $1 \mathrm{mM}$ EDTA). RNase A (Worthington diagnostics; boiled for $10 \mathrm{~min}$ to inactivate the DNase) was added to a concentration of $100 \mu \mathrm{g} / \mathrm{ml}$, and the samples were incubated at $37^{\circ} \mathrm{C}$ for $30 \mathrm{~min}$. Samples were then reextracted with SEVAG, and the aqueous phase was transfered to a fresh tube. A $50-\mu l$ portion of $7.5 \mathrm{M}$ ammonium acetate was added, and the DNA was precipitated with two volumes of ice-cold 95 or $100 \%$ ethanol. The DNA usually precipitated immediately and was pelleted by centrifugation in a microcentrifuge for $30 \mathrm{~s}$. This pellet was suspended in $300 \mu \mathrm{l}$ of $0.2 \mathrm{M}$ ammonium acetate and reprecipitated with two volumes of ice-cold ethanol. The final pellet was dried briefly under a vacuum and resuspended in $50 \mu \mathrm{l}$ of TE. The usual yield from $40 \mathrm{mg}$ of lyophilized tissue was 8 to $10 \mu \mathrm{g}$ of DNA.

Digestion of DNA. DNA samples were digested with $\mathrm{HpaII}$ (New England BioLabs, Inc., or Bethesda Research Laboratories, Inc.) or MspI (New England BioLabs) in buffers suggested by the manufacturers. The usual digestion conditions were $16 \mathrm{U}$ of enzyme per $2 \mu \mathrm{g}$ of DNA, with incubation at $37^{\circ} \mathrm{C}$ for $3 \mathrm{~h}$.

Filter hybridization. Gel electrophoresis, Southern transfer, and DNA labeling were as previously described (21) except that Zetabind (AMF Inc.) was used as the hybridization membrane. Hybridizations were either in 50\% formamide (as described by the manufacturer) or in aqueous buffers (as described by Maniatis et al. [10] except that $20 \mathrm{mM}$ sodium pyrophosphate [pH 7.0] was added to all buffers). The probe used for all of the blots in this paper was the 0.4-kb SmaI puc12 subclone described by Zolan and Pukkila (Zolan and Pukkila, in press). For some of the bl.ts, the entire clone was labeled with ${ }^{32} \mathrm{P}$ by nick translation. Alternatively, the $0.4-\mathrm{kb}$ insert was electroeluted from agarose, nick translated, and ligated (10). Usual specific activities were $10^{8} \mathrm{cpm} / \mu \mathrm{g}$.

\section{RESULTS}

Variability of methylation in meiotic progeny. We have previously identified a single-copy, centromere-linked sequence, termed 16-1, that is methylated in one strain of $C$. cinereus and not in others (Zolan and Pukkila, in press). Tetrads from a cross between the methylated strain, Okayama-7, and strain PJP52, which is not methylated at locus 16-1 (cross MZ1, Table 1), were analyzed for methylation at locus 16-1 and for the parental origin of the locus. This was possible because the two parental strains differ both in the methylation state of this region and at the sequence level: Okayama-7 carries a large insertion relative to PJP52, and there is also a restriction site polymorphism between the two strains (21). Thus, a $0.4-\mathrm{kb}$ SmaI subclone of sequence 16-1 hybridizes to a $2.5-\mathrm{kb}$ fragment when total DNA from Okayama-7 is digested with HpaII (Fig. 1A, lane a) and a 1.0-kb fragment when Okayama-7 DNA is digested with MspI (Fig. 1A, lane b). In contrast, a 1.5-kb band is observed when total DNA from PJP52 is cut with either HpaII or MspI (Fig. 1A, lanes c and d). By comparing the HpaII and MspI patterns of a given strain, the presence or absence of methylation at locus 16-1 can be determined. By comparing the MspI patterns of progeny with those of the parents, the parental origin of locus 16-1 can be determined.

In each of the 12 tetrads examined, two of the progeny were methylated, and two were not. The two that were methylated had received the chromosome carrying locus 16-1 from the methylated parent, Okayama-7. In nine tetrads, the methylation patterns of the methylated progeny were identical to that of Okayama-7. However, in three of the tetrads, one or more methylated progeny had methylation patterns different from that of the methylated parent. One such tetrad is shown in Fig. 1B. Two members of this tetrad were identical to the nonmethylated parent, PJP52 (Fig. 1B, lanes a and b, g and h). Two of the progeny had received the chromosome carying locus 16-1 from Okayama7, since each contained a 1.0-kb MspI fragment (Fig. 1B, lanes d and f). However, the Hpall fragments in these two strains were $5.2 \mathrm{~kb}$ in size (Fig. 1B, lanes c and e), whereas Okayama-7 DNA is cut into a $2.5-\mathrm{kb}$ fragment homologous to the same probe (Fig. 1A, lane a). Deliberate partial digestion of Okayama-7 DNA with MspI showed that the change from the $2.5-\mathrm{kb}$ fragment to the 5.2-kb HpaII fragment involved the methylation of at least four more sites (data not shown). The increase in size of the HpaII fragments in two of the meiotic progeny shown in Fig. 1 was not due to changes at the sequence level, because the MspI fragments of the progeny were identical to that of Okayama7 (Fig. 1). The 5.2-kb HpaII fragments were also not the result of inadvertent partial digestion of those progeny DNAs with HpaII. This was shown by an experiment in which we digested Okayama-7 DNA with up to 32-fold less

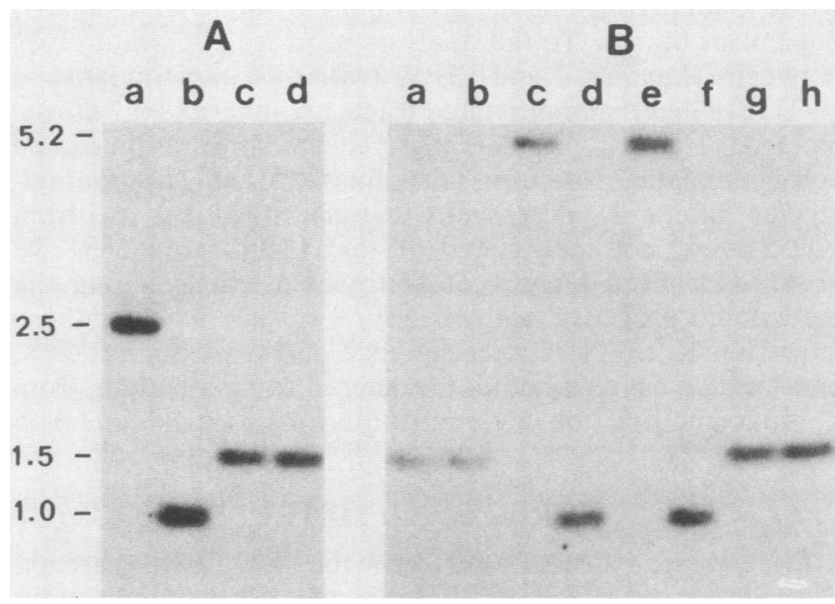

FIG. 1. Tetrad analysis of cross MZ1. DNAs from Okayama-7 (A, lanes $\mathrm{a}$ and $\mathrm{b}$ ), PJP52 (A, lanes $\mathrm{c}$ and d), and progeny (one tetrad is shown in panel $B$ ) of cross MZ1 were isolated and digested with HpaII (A, lanes a and c; B, lanes a, c, e, and g) or MspI (A, lanes b and $d ; B$, lanes $b, d, f$, and $h)$. The fragments were then separated on a $1 \%$ agarose gel, transferred to Zetabind, and hybridized to a $0.4-\mathrm{kb}$ SmaI clone homologous to locus 16-1. Fragment sizes are given at the left in kilobase pairs. 

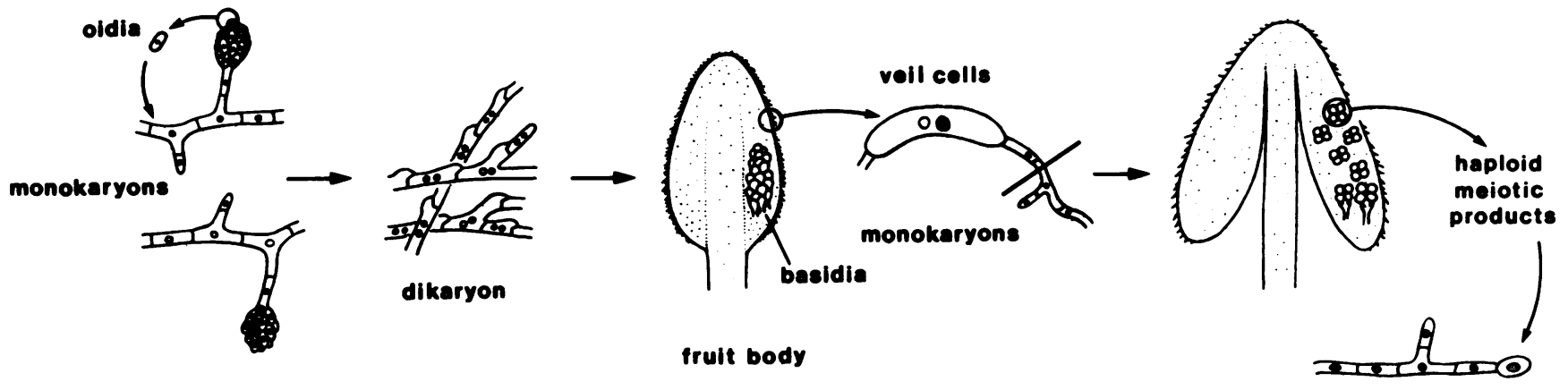

FIG. 2. Life cycle of $C$. cinereus. The portions of the life cycle that were examined for methylation variation are depicted. Oidia are mitotically derived, haploid spores produced by monokaryons. They germinate to repeat the haploid portion of the life cycle. Two compatible monokaryons fuse and form stable dikaryons, which differentiate into fruiting bodies. Veil cells are dikaryotic and can be resolved, by mechanical disruption, into the two parental monokaryons of the dikaryon. Within the basidia, on the face of the gills of the fruiting body, the two nuclei of the dikaryon fuse and undergo meiosis. The four haploid nuclei, the products of meiosis, migrate into spores, on top of the basidia. These basidiospores germinate into monokaryons.

enzyme than in our standard conditions (16 U of HpaII per $2 \mu \mathrm{g}$ of DNA, incubation at $37^{\circ} \mathrm{C}$ for $3 \mathrm{~h}$ ). Even a 32 -fold reduction in enzyme concentration failed to generate a prominent 5.2-kb HpaII fragment from Okayama-7 DNA, although a faint 5.2-kb $\mathrm{HpaII}$ fragment was visible upon long exposure of the autoradiograms. In addition, the digestion of highly methylated progeny DNA from a different cross with increasing amounts of enzyme did not change the appearance of the 5.2-kb HpaII fragments from the DNAs of those strains (data not shown).

Mitotic versus meiotic methylation variation. We wished to determine whether the changes in methylation we observed in the tetrads of the cross MZ1 were due to special properties of meiotic methylation in $C$. cinereus. It was possible that de novo methylation of DNA sequences was more frequent after premeiotic DNA replication than after replication during vegetative growth. To investigate the relative effects of mitosis and meiosis on the variability of DNA methylation patterns, we compared methylation variability in cells that had undergone approximately the same number of rounds of DNA replication, as judged by colony size, but which differed in whether they had been through meiosis or through mitotic divisions only. For this experiment, we took advantage of the fact that dikaryotic cells from the outer covering of the fruiting body (veil cells) can be removed and plated and frequently give rise to monokaryotic colonies (Fig. 2). After the removal of veil cells, a given fruiting body was allowed to continue development until spores dropped, about $24 \mathrm{~h}$ later. Random basidiospores were collected, and total DNA was isolated and analyzed from both the veil cell isolates, which were mitotic products, and the basidiospore isolates, which were meiotic products. With the veil cell isolates, it was possible to distinguish morphologically between isolates that derived from Okayama-7 nuclei and those that derived from PJP52 nuclei. Only the isolates of Okayama-7, the methylated parent, were analyzed, since our tetrad analysis had demonstrated that no methylation of locus 16-1 ever occurred on the PJP52 chromosome. Therefore, all of the veil cell isolates had the Okayama-7 locus 16-1 (Fig. 3A). For the basidiospore isolates, no morphological features could be used to determine which isolates would have the Okayama-7 locus 16-1. Therefore, both methylated and unmethylated (displaying the PJP52 1.5-kb HpaII fragment) isolates were obtained (Fig. 3B).

Both veil cell isolates and basidiospore isolates showed variability in the methylation of locus $16-1$, and both were variable with similar frequency (Fig. $3 \mathrm{~A}$ and $\mathrm{B}$; Table 2). In both cases, about $20 \%$ of the isolates had methylation patterns different from that of the methylated parent, Okayama-7. All the differentially methylated progeny had higher-molecular-weight HpaII fragments than the methylated parent. All but two had a 4.5-kb HpaII fragment. One veil cell isolate had a 3.6-kb HpaII fragment, and one basidiospore isolate had a 5.2-kb HpaII fragment, similar to that seen in the tetrad shown in Fig. 1.

Since veil cell and basidiospore isolates show similar frequencies of methylation variation, variability in the inheritance of DNA methylation patterns is not a specific result of the meiotic process in $C$. cinereus. However, it was possible that such variability is confined to differentiated cells of the fruiting body (Fig. 2) and that methylation patterns do not vary during replication of the monokaryon. To determine whether the inheritance of DNA methylation patterns is also variable during vegetative growth of monokaryons, we examined oidial isolates of the methylated parent, Okayama-7, to determine whether methylation heterogeneity existed among the nuclei of this haploid strain. The plate used to make the cross MZ1 was subcultured, and oidia were isolated from that direct subculture. Total DNA was prepared from 41 of these oidial isolates, digested with HpaII, and analyzed by Southern blotting. Of the oidial DNAs, $5 \%$ generated a 4.5-kb HpaII fragment, and the remainder generated the previously observed 2.5-kb $\mathrm{HpaII}$ fragment (Fig. 3C; Table 2). Since this strain was derived from a single basidiospore isolate (D. Moore, personal communication), variation in methylation had arisen during vegetative replication of its DNA.

Stability of higher levels of methylation. The change from the Okayama-7 methylation pattern, the 2.5-kb HpaII fragment of locus 16-1, to the higher levels of methylation seen in meiotic and mitotic progeny usually involved the methylation of several additional $\mathrm{HpaII}$ sites and an increase in HpaII fragment size by several kilobases (Fig. 1 and 3). One of the basidiospore progeny of cross MZ1, strain MZ1-23C, was initially identified as having methylation at the level of the methylated progeny of tetrad 15 (shown in Fig. 1). However, after several months of serial subculture and storage at $4^{\circ} \mathrm{C}$, DNA from isolate $\mathrm{MZ1-23C}$ generated a 2.5-kb HpaII fragment of locus 16-1. In fact, the methylation pattern of locus 16-1 in isolate MZ1-23C was now exactly the 

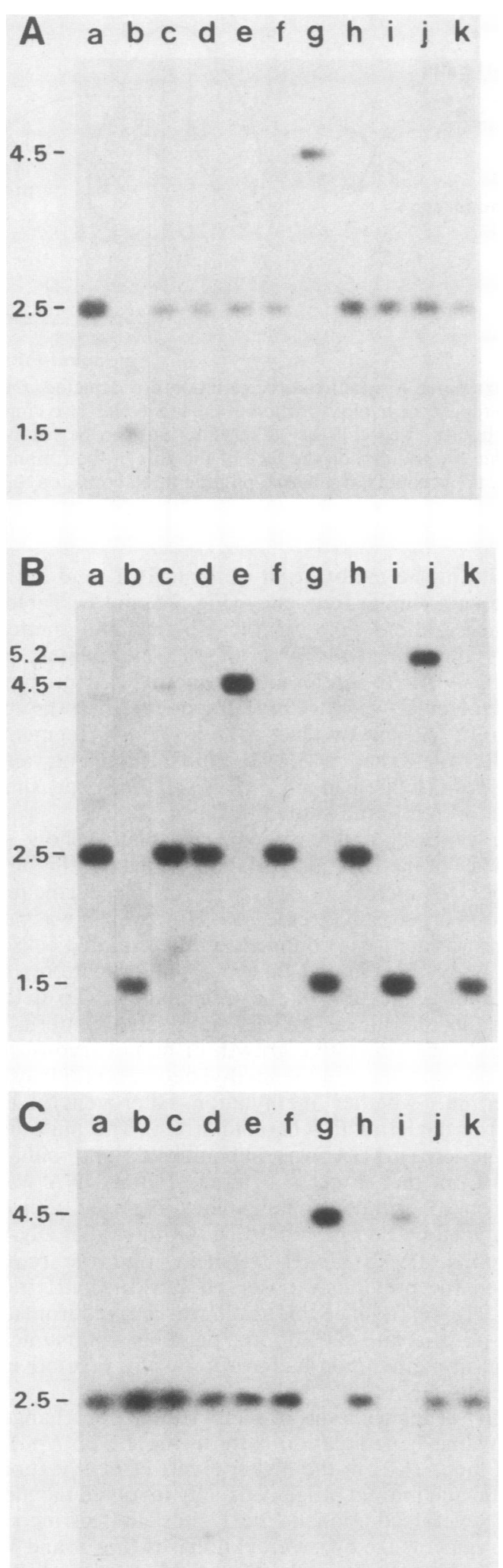

FIG. 3. Comparison of methylation variation in mitosis and meiosis. DNA was isolated from veil cells of cross MZ1 (A), basidiospores of cross MZ1 (B), and oidia of strain Okayama-7 (C). All DNAs were digested with $\mathrm{HpaII}$ and analyzed as described in the legend to Fig. 1. In panels A and B, parental DNAs (Okayama-7, lane a, and PJP52, lane b), also digested with HpaII, are included for comparison. Fragment sizes are given at the left in kilobase pairs.
TABLE 2. Meiotic versus mitotic methylation variation

\begin{tabular}{lccc}
\hline \multirow{2}{*}{ Source of strains } & \multicolumn{2}{c}{$\begin{array}{c}\text { No. of isolates with fol- } \\
\text { lowing methylation } \\
\text { pattern: }\end{array}$} & \% Variation \\
\cline { 2 - 3 } & Parental & Variant & \\
\hline MZ1 veil cells & 37 & 8 & 18 \\
MZ1 basidiospores & 22 & 6 & 21 \\
Okayama-7 oidia & 39 & 2 & 5 \\
\hline
\end{tabular}

same as that of Okayama-7, the methylated parent of cross MZ1. Analysis of several nutritional markers present in the strain indicated that this was not a case of mismarked or switched strains. Thus, it appeared that these longer methylated tracts were not completely stable. To examine the stability of these longer methylated tracts more directly, two progeny, MZ2-21 and MZ2-22, of cross MZ2 (Table 1) that had the same 5.2-kb HpaII methylation pattern of locus 16-1 were crossed to each other (cross MZ3, Table 1) and induced to fruit, and the methylation patterns of random basidiospore isolates were determined.

The 5.2-kb HpaII fragment pattern of methylation was stable through dikaryon formation, fruiting, and meiosis. Of 48 basidiospore isolates analyzed, only 2 had lost methylation (Fig. 4). Interestingly, these two isolates had lost methylation of at least five $\mathrm{HpaII}$ sites. DNA from isolate MZ3-19 generated a 1.4-kb HpaII fragment (Fig. 4B, lane b). This means that methylation was lost even from sites that were methylated in Okayama-7, the original methylated strain from which all of these isolates were derived. It also means that the loss from isolate MZ1-23C was not a reversion to some "proper" level of methylation, i.e., that present in Okayama-7. The other isolate of cross MZ3 that lost methylation was identical to MZ3-19. One isolate of cross MZ3 had gained methylation at one HpaII site, and the remaining isolates were identical to the parents.

Meiotic inheritance of different methylation patterns. The first cross of our study, MZ1, was a cross between a strain

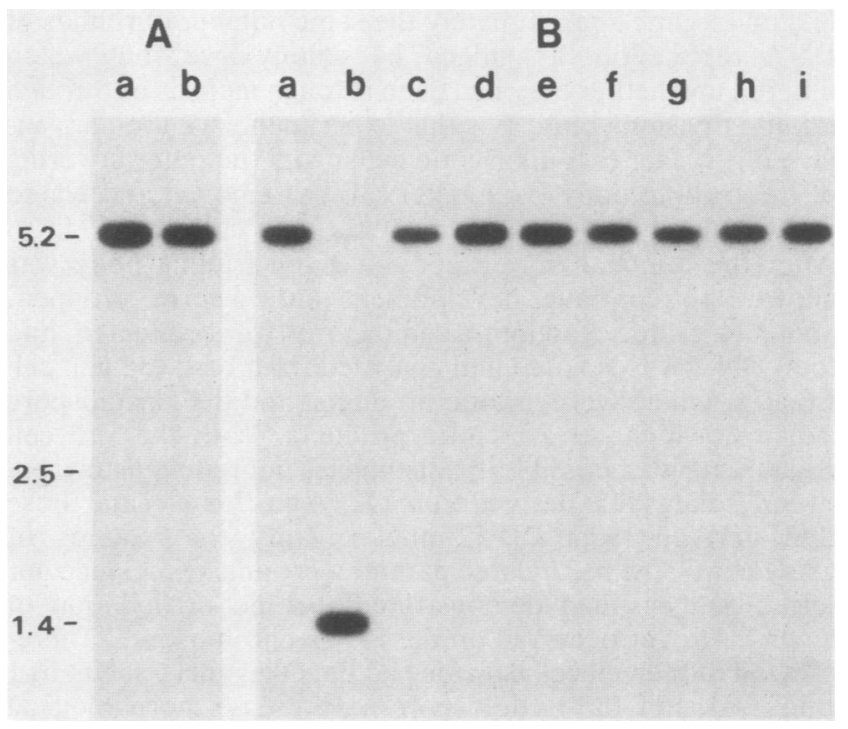

FIG. 4. Inheritance of de novo methylation. DNAs from the parents (A) and random basidiospores (B) of cross MZ3 were isolated, digested with HpaII, and analyzed as described in the legend to Fig. 1. Fragment sizes are given at the left in kilobase pairs. 
methylated at locus 16-1 (Okayama-7) and a strain not methylated at locus 16-1 (PJP52). We never saw any evidence for methylation of the PJP52 chromosome. Therefore, we concluded that the methylation of one chromosome has no effect on the methylation of its homolog and that methylated and unmethylated tracts, if not exact patterns, are inherited faithfully through meiosis in $C$. cinereus (Zolan and Pukkila, in press). However, the two parents of cross MZ1 are significantly different at the sequence level. Although locus 16-1 of strain PJP52 does contain nonmethylated HpaII sites, too little is known about the signals for eucaryotic DNA methylation for us to have been sure that these sites were actually potential sites of methylation of locus 16-1. Therefore, to assess possible effects of the methylation of one chromosome on the methylation of its homolog during meiosis, we crossed strain MZ2-28, whose DNA generated a 5.2-kb HpaII fragment homologous to the probe for locus 16-1, with strain Okayama-7 (cross MZ4, Table 1). These strains were identical at the sequence level but differed only in their methylation patterns at locus 16-1.

We analyzed both random basidiospores and tetrads from cross MZ4. Of the random basidiospores, 7 of $17(41 \%)$ were identical to Okayama-7 and 10 of 17 (59\%) were identical to MZ2-28. We examined progeny of five complete tetrads and confirmed that the inheritance of methylation patterns at locus 16-1 was 2:2 in this cross (Fig. 5). Therefore, altered methylation patterns can be transmitted through meiosis, and there appears to be no influence of the methylation pattern of one chromosome on its homolog during the meiotic process.

\section{DISCUSSION}

There are two striking features of our data. First, although we observed faithful transmission of methylated tracts during mitotic and meiotic divisions, we found that the number of methylated sites in these tracts could vary. Most of the methylation variation we observed involved increases in the

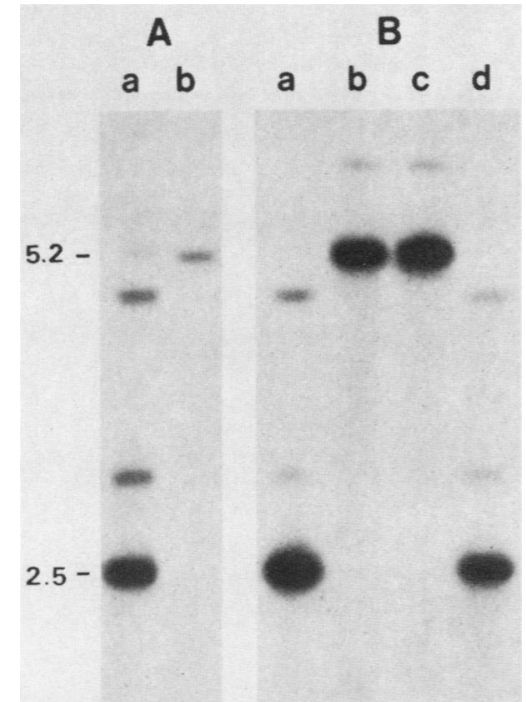

FIG. 5. Meiotic inheritance of different methylation patterns. DNAs from Okayama-7 (A, lane a), strain MZ2-28 (A, lane b), and progeny of a cross between these two strains (cross MZ4; one tetrad is shown in panel B) were digested with HpaII and analyzed as described in the legend to Fig. 1. Fragment sizes are given at the left in kilobase pairs. amounts of methylation, although we did see occasional losses. It is apparent that the gains must eventually be balanced by the losses, since the predominant methylated fragment from locus $16-1$ in Okayama-7 $(2.5 \mathrm{~kb})$ was not the largst fragment we observed in these experiments. The largest fragment ever observed was $7.4 \mathrm{~kb}$ in size. This fragment is seen as a band of low intensity in Fig. 5B, lanes $\mathrm{b}$ and $\mathrm{c}$, and was also observed in HpaII-digested DNA samples isolated from basidiospore progeny of cross MZ2. The precise environmental conditions which might favor one process or the other are unknown, although we did observe loss of methylation after prolonged subculture and storage at $4^{\circ} \mathrm{C}$. Methylated tracts at locus 16-1 were not among the largest tracts observed in ethidium bromide-stained $\mathrm{HpaII}$ digests, as these could exceed $25 \mathrm{~kb}$ (Zolan and Pukkila, in press). We never saw, in oidial isolates, veil cell isolates, or basidiospore isolates, strains whose DNAs generated $\mathrm{HpaII}$ fragments of locus $16-1$ that were greater than $7.4 \mathrm{~kb}$. The reason for this could be that the next HpaII site is not a substrate for the DNA methylase and can never be methylated. Alternatively, maintenance of the unmethylated state at that site may be critical for the function of that region of the genome. In all of our HpaII-digested DNA samples, bands of different intensities were observed (seen most clearly in Fig. 5). Each DNA preparation was from a culture derived from a single cell: an oidium, a veil cell, or a basidiospore (this was ensured by microscopic examination of each isolate). Therefore, the observed heterogeneity in methylation must have arisen during the mitotic growth of each culture.

We also observed that altered methylated tracts resulting from de novo methylation were transmitted through meiosis (crosses MZ3 and MZ4, Fig. 4 and 5, respectively). This result clearly shows that detection of these larger fragments was not an artifact arising from partial digestion but that these fragments had sustained heritable alterations in DNA methylation. The function of locus $16-1$ is unknown. The strains that are methylated at this locus also contain an insertion (relative to all other strains so far examined) in that region of the chromosome (21), but the precise boundaries of the methylated tract relative to the insertion have not been defined. Our results are consistent with the concept of allowed drift of methylation patterns in certain regions of the genome $(16,19,20)$, although the presence or absence of methylated tracts appears to be maintained faithfully. The isolation of mutants unable to methylate their DNA would facilitate analysis of the functions and dispensability (11) of DNA methylation in eucaryotes that normally carry out this modification. The high levels of 5-methylcytosine in $C$. cinereus DNA and the ease of genetic manipulation of this organism should make this basidiomycete a good model system for studies of the functions of eucaryotic DNA methylation.

\section{ACKNOWLEDGMENTS}

We thank J. Cassidy for help with tetrad analysis of cross MZ1, B. Lu for teaching us the veil cell isolation procedure, S. Whitfield for illustrations, M. Madouse for secretarial assistance, C. Skrzynia, R. C. Brown, and D. Kleinhans for technical assistance, and L. Casselton for assistance with DNA isolation. We also thank $\mathrm{J}$. Cassidy, D. Binninger, B. Yashar, and E. Selker for helpful discussion and $\mathbf{J}$. Palmer for critical reading of this manuscript.

This investigation was supported by Public Health Service grant 5 F32 CA07395, awarded to M.E.Z. by the National Cancer Institute and by National Science Foundation grant PCM8215694 awarded to P.J.P. 


\section{LITERATURE CITED}

1. Anderson, G. E. 1971. The life history and genetics of Coprinus lagopus. Harris Biological Supplies, Weston-super-Mare, England.

2. Antequera, F., M. Tamame, J. R. Villaneuva, and T. Santos. 1984. DNA methylation in the fungi. J. Biol. Chem. 259: 8033-8036.

3. Bird, A. P., and E. M. Southern. 1978. Use of restriction enzymes to study eukaryotic DNA methylation. I. The methylation pattern in ribosomal DNA from Xenopus laevis. J. Mol. Biol. 118:27-47.

4. Cassidy, J. R., D. M. Moore, B. C. Lu, and P. J. Pukkila. 1983. Unusual organization and lack of recombination in the ribosomal RNA genes of Corpinus cinereus. Curr. Genet. 8: 607-613.

5. Cedar, H. 1984. DNA methylation and gene expression, p. 147-164. In A. Razin, H. Cedar, and A. D. Riggs (ed.), DNA methylation: biochemistry and biological significance. SpringerVerlag, New York.

6. Dutta, S., and M. Ojha. 1972. Relatedness between major taxonomic groups of fungi based on the measurement of DNA nucleotide sequence homology. Mol. Gen. Genet. 114:232240.

7. Groudine, M., and K. F. Conklin. 1985. Chromatin structure and de novo methylation of sperm DNA: implications for activation of the paternal genome. Science 228:1061-1068.

8. Holliday, R., and J. E. Pugh. 1975. DNA modification mechanisms and gene activity during development. Science 187: 226-232.

9. Kaput, J., and T. W. Sneider. 1979. Methylation of somatic vs. germ cell DNAs analyzed by restriction endonuclease digestions. Nucleic Acids Res. 7:2303-2322.

10. Maniatis, T., E. F. Fritsch, and J. Sambrook. 1982. Molecular cloning, a laboratory manual. Cold Spring Harbor Laboratory,
Cold Spring Harbor, N.Y.

11. Marinus, M. G., M. Carraway, A. Z. Frey, L. Brown, and J. A. Arraj. 1983. Insertional mutations in the dam gene of Escherichia coli K-12. Mol. Gen. Genet. 192:288-289.

12. Moore, D. 1966. New method of isolating the tetrads of agrics. Nature (London) 209:1157-1158.

13. Murray, M. G., and W. F. Thompson. 1980. Rapid isolation of high molecular weight plant DNA. Nucleic Acids Res. 7:1869-1885.

14. Razin, A., and A. D. Riggs. 1980. DNA methylation and gene function. Science 210:604-610.

15. Saghai-Maroff, M. A., K. M. Soliman, R. A. Jorgensen, and R. W. Allard. 1984. Ribosomal DNA spacer-length polymorphisms in barley: mendelian inheritance, chromosomal location, and population dynamics. Proc. Natl. Acad. Sci. USA 81: 8014-8018.

16. Shmookler Reis, R. J., and S. Goldstein. 1982. Variability of DNA methylation patterns during serial passage of human diploid fibroblasts. Proc. Natl. Acad. Sci. USA 79:3949-3953.

17. Vanyushin, B. F., S. G. Tkacheva, and A. N. Belozersky. 1970. Rare bases in animal DNA. Nature (London) 225:948-949.

18. Waalwijk, C., and R. A. Flavell. 1978. MspI, an isoschizomer of HpalI which cleaves both unmethylated and methylated Hpall sites. Nucleic Acids Res. 5:3231-3236.

19. Wolf, S. F., D. J. Jolly, K. D. Lunnen, T. Friedman, and B. R. Migeon. 1984. Methylation of the hypoxanthine phosphoribosyltransferase locus on the human $\mathrm{X}$ chromosome: implications for X-chromosome inactivation. Proc. Natl. Acad. Sci. USA 81:2806-2810.

20. Wolf, S. F., and B. R. Migeon. 1982. Studies of X chromosome DNA methylation in normal human cells. Nature (London) 295:667-671.

21. Wu, M. M. J., J. R. Cassidy, and P. J. Pukkila. 1983. Polymorphisms in DNA of Coprinus cinereus. Curr. Genet. $7: 385-392$. 